\title{
Clinical supervision at a magnet hospital: A review of the preceptor-facilitator model
}

\author{
Natasha Frances Franklin, Sandra Leathwick, Michelle Phillips \\ St Vincent's Private Hospital, Sydney, Australia. \\ Correspondence: Natasha Frances Franklin. Address: St Vincent's Private Hospital, Sydney, Australia. \\ Email: nfranklin@stvincents.com.au \\ Received: March 21, 2013 \\ Accepted: April 24, 2013 \\ Online Published: September 2, 2013 \\ DOI : $10.5430 /$ jnep.v4n1p134 \\ URL: http://dx.doi.org/10.5430/jnep.v4n1p134
}

\section{Abstract}

Background: The demand for clinical placements and quality clinical supervision for nursing students remains an international issue. In light of on-going concerns related to recruitment and retention of nurses and constraints on fiscal resources both in education and healthcare, the aim of this review was to compare the "preceptor-facilitator" clinical supervision model used at a Magnet hospital against the "preceptor" and "facilitator" clinical supervision models frequently used in the clinical learning environment in Australia.

Methods: A qualitative-descriptive review was undertaken using first, second and third year undergraduate nursing student evaluations $(\mathrm{n}=93)$. Evaluations were completed during the last three days of students' clinical placement using an electronic questionnaire. The questionnaire tool used open and closed questions to examine three main concepts: student-preceptor supervision; student-facilitation supervision; and the clinical learning environment.

Findings: Three main themes emerged from the review. Firstly, how undergraduate nursing students highly valued the facilitator-student relationship; secondly, the importance of "support” as being an integral part of students' clinical learning experience and thirdly; the recognition of students being considered as part of the health care team and a valued contributor towards patient care.

Conclusion: The preceptor-facilitation model described and evaluated in this review offers an excellent clinical supervision framework to support, nurture and foster a positive clinical learning environment for nursing students. This model of clinical supervision strategically aims not only to provide nursing students with high quality clinical supervision but offers nurses a supportive environment as preceptors and professional development opportunities through clinical facilitation. This review does highlight that there is a need for more research regarding the use of the preceptor-facilitator model to include the perspectives of both education and healthcare providers.

\section{Key words}

Clinical learning environment, Clinical supervision, Quality clinical supervision, Health Workforce Australia, Preceptorfacilitation model, Student perspectives

\section{I ntroduction}

It is undisputed that globally the demand for clinical placements for nursing students is increasingly challenging and providing quality clinical supervision can be complex. Factors impacting clinical supervision include: workforce shortage- 
es leading to a lack of clinical supervisors; workforce skill-mix leading to a lack of appropriately trained and skilled clinical supervisors; increasing patient demand on clinical services; increasing acuity and complexity of patient and resource constraints ${ }^{[1]}$. For these reasons healthcare providers have reported problems with the capacity to not only provide quality clinical placements but to increase student capacity as well ${ }^{[2]}$. In Australia, in response to the above, a council of governments in 2008 formed Health Workforce Australia to address the on-going challenges of not only finding clinical placements for nursing students but providing high-quality clinical placements ${ }^{[1]}$.

This review offers an exploration of these issues by firstly outlining the five clinical supervision models identified by HWA while offering a more detailed discussion about the preceptor and facilitation clinical supervision models that are more commonly used in the clinical learning environment in Australia. This review also aims to descriptively describe the clinical supervision model used at a private Magnet hospital in Australia to demonstrate that quality clinical supervision can be achieved using the preceptor-facilitator clinical supervision model.

\section{Background}

Despite recent media attention related to a shortfall of graduate nursing positions in Australia, recruitment and retention of nurses is an on-going issue for health care organisations with a concerning predicted shortfall of approximately 110,000 nurses in the next decade, particularly in aged-care ${ }^{[1,3]}$. Health Workforce Australia is driving both education and healthcare reform in Australia advocating that both education and healthcare providers must empower nursing students to work to the best of their ability by providing a clinical learning environment that is safe, motivating and stimulating. One method of achieving this is through quality clinical supervision ${ }^{[1,4]}$. Clinical supervision is defined as:

"involving the oversight - either direct or indirect, by a clinical supervisor of professional procedures and/or processes performed by a student or a group of students within a clinical placement for the purpose of guiding, providing feedback on, and assessing personal, professional and educational development in the context of each student’s experience of providing safe, appropriate, and high quality patient care” ${ }^{[4]}$.

Table 1: Health Workforce Australia Clinical Supervision Models

\begin{tabular}{ll}
\hline Model & Components of clinical supervision model \\
\hline Preceptor & A 1:1 model where a student is assigned to a registered nurse who is known as the \\
'preceptor'. The student works alongside the preceptor on a day-to-day basis to provide \\
direct and indirect supervision and undertakes summative and formative assessments. \\
A 1:6 or 1:8 model where a registered nurse directly and indirectly supervises a group of \\
students. Facilitators are either university employed or hospital employed staff and \\
undertake both summative and formative assessments. \\
A combination of the preceptor and facilitation/supervision model where a student is \\
allocated (or otherwise labelled as 'buddied') to a registered nurse for preceptoring and \\
the facilitator undertakes group supervision of 1:8 or more. \\
A combined model of the preceptor and facilitator model with the added component that \\
there is a partnership between the health service and university and there is Clinical \\
Liaison Nurse, or more commonly titled 'Nurse Educator' that provides the link to the \\
university. \\
A model that is similar to the preceptor model but is less commonly used in undergraduate \\
clinical education as the clinical supervision is more often than not, indirect. The mentor \\
model involves a longer term relationship between the student and the registered nurse.
\end{tabular}

It is endeavoured that "quality” clinical supervision will be achieved by: increasing health facility capacity; minimising tension between educational and health service delivery and using clinical supervisors' time effectively and efficiently. While there is a variety of clinical supervision models referred to in the literature including: the growth and support model, the integrative approach model, the cluster model, and the more well-known Heron's intervention analysis framework and the Proctor model ${ }^{[5-10]}$, Health Workforce Australia describes five main clinical supervision models for the clinical 
learning environment including: the preceptor model; the facilitator model; the preceptor-facilitator model; the mentor model; and the dedicated education model as outlined in Table 1.

\section{Preceptor model}

Despite Health Workforce Australia's move to simplify the clinical supervision models into five categories, there is still a lack of clarity and direction within the literature which clinical supervision best meets the learning objectives of undergraduate nurses and which supervision model best supports nursing students to make the successful transition to graduate nurses. In Australia, the preceptor model has been predominantly the more popular and utilised model in the clinical learning environment. There has however, been an apparent shift away from this model to the either the "facilitator" or "preceptor-facilitator" model mainly due to the varying and multiple roles and responsibilities of the preceptor ${ }^{[11]}$. Concerns related to the preceptor model include: preceptors' concerns about increased clinical workloads and increasing patient acuity while trying to balance the role and responsibilities of a clinical supervisor; the lack of formal education and training for preceptors how to clinical supervise and how to perform formal summative and formal assessments; the expectation from the health care employers not only to preceptor nursing students, but preceptor new graduate nurses, post-graduate nurses and new staff members; and finally, the expectation for all nurses to preceptor students all of which directly impacts the willingness and ultimately behaviour of the preceptor supervising the student ${ }^{[12-17]}$. Similarly, for many reasons students can be allocated multiple preceptors during their clinical placement which can have a detrimental impact on the student's clinical learning environment ${ }^{[16-17]}$.

\section{Facilitator model}

With a move away from the preceptor model towards the facilitation clinical supervision model, the facilitator model has gained the attention of both education and health care providers to not only support and facilitate the clinical learning environment of nursing students but to help relieve the workload pressures of preceptors. In recent studies, the facilitator model has been reported as having a more positive impact on the clinical learning environment by students as they perceive the facilitation model as a better model for the development of critical thinking, linking theory to practice and overall improved clinical competence ${ }^{[18-20]}$. Nursing students also prefer the facilitation model to the preceptor model due to the perception of having more one-on-one time with their facilitators caused by either staff shortages or students' perceived "busyness" of the clinical learning environment and/or being allocated to multiple preceptors ${ }^{[18-21]}$. Similarly, the facilitator model is also viewed favourably by clinical facilitators as they are able to concentrate solely on the student's clinical learning objectives while not having to try and balance patient care while preceptoring students and view facilitating nursing students as an opportunity to further professional development ${ }^{[21]}$.

In Australia, clinical facilitators mainly derive from two main sources. "Sessional” facilitators are nurses employed by the university to facilitate students in varying health care facilities. However, some of the issues pertaining to the recruitment of sessional facilitators are that facilitators do not usually work in the health care facility in which they are facilitating students and are therefore unaware of the clinical learning environment and are unfamiliar with the preceptors, nurse educators and nurse managers ${ }^{[22]}$. Sessional facilitators can also often be facilitating students across more than one healthcare facility and therefore time spent with individual students is often significantly reduced ${ }^{[4]}$. Sessional facilitators can be seen as the "middle" person as they are neither employed by the educational or healthcare provider on full-time or permanent basis, but rather on a "casual” or "ad-hoc" basis. Due to the casual nature of this employment and limited career opportunities/advancement "quality" sessional facilitators can be difficult to recruit ${ }^{[4]}$. "Academic" facilitators are university-employed lecturers who conduct 'site' visits to their nursing students. The use of academic facilitators often results in significant lack of facilitation due to time constraints when fulfilling this role simultaneously with their academic

teaching and research commitments ${ }^{[23]}$. More often than not, they are only involved when there are student related performance issues ${ }^{[23]}$.

\section{Preceptor-facilitator model}

The preceptor-facilitator model is a combination of the preceptor and the facilitator model as described in table 1 . Although there is a paucity within the literature evaluating the effectiveness of the preceptor-facilitation model in the 
clinical learning environment it is advocated that the role of the clinical facilitator compliments the preceptor model as both the facilitator and preceptor have a major influence on undergraduate nursing students ${ }^{\text {[24] }}$.

The clinical supervision model used at St Vincent's Private Hospital (Sydney) in Australia is the preceptor-facilitator clinical supervision model. St Vincent's Private Hospital is internationally and nationally recognised for its dedication and commitment to nursing excellence and person centred care and in 2011 St Vincent's Private Hospital was received Magnet designation. The preceptor-facilitator model at St Vincent's Private Hospital allocates a nursing student to a preceptor and then a clinical facilitator is then assigned to eight nursing students and is responsible for the overall clinical supervision, management and assessment of the nursing students. One significant difference of the clinical supervision model at St Vincent's Private Hospital compared to other health care facilities is that clinical facilitators are clinical nurses from within the organisation. Clinical facilitators are recruited and managed by the education department at St Vincent's Private Hospital and facilitators are required to have a minimum three years post-graduate clinical experience and have previous experience of preceptoring students and have completed clinical supervision education in the form of preceptor and facilitator workshops. These requirements are supported by the literature which recognises that clinical facilitators are required to be clinically competent and experienced, possess highly efficient communication skills as well as showing leadership and commitment to the learning experiences of nursing students ${ }^{[24]}$.

With a dedicated commitment to recruitment and retention of nurses through the undergraduate nursing program, students are invited to complete an online evaluation tool about their clinical learning environment during their clinical placement at St Vincent's Private Hospital.

\section{Methods}

A qualitative-descriptive review was undertaken to evaluate the feedback of nursing students undertaking clinical placements at St Vincent's Private Hospital in Sydney. Prospective approval was obtained from the hospital's nursing executive to undertake the review this review was "low-risk" no ethics approval was sought from the hospital's ethics committee as the clinical placement evaluation tool is an existing evaluation tool used in the hospital's clinical learning environment to appraise the feedback of students' clinical placements.

Ninety-three evaluations from first, second and third year nursing students were reviewed and no identifying information (such as; the students' university) was collected. The inclusion criteria consisted of all first, second and third year nursing students enrolled in an undergraduate nursing program from one of the three preferred partnering universities from the same twelve month period. The evaluation tool used a 5-point Likert Scale (strongly agree, agree, neutral, disagree and strongly disagree) and open-ended questions. The evaluations were completed during the last three days of their clinical placement.

The evaluation tool was based on the clinical learning environment inventory ${ }^{[25]}$, designed to assess three main areas of the clinical learning environment including: the effectiveness of the preceptor-facilitator model, appraising the role of the preceptor; facilitator clinical supervision; and the clinical learning environment. In regards to preceptor clinical supervision, students were asked to evaluate three key areas including: satisfaction with their preceptor allocation; the attitude of their preceptor regarding supporting their learning needs, and to evaluate from their perspective, the preceptor's knowledge and skills. Evaluation of clinical facilitation supervision assessed four areas including: the student's relationship with the facilitator; facilitator created learning opportunities; the facilitator's clinical knowledge and skill; and the facilitator's feedback. The last component assessed the clinical learning environment by evaluating the students' perspectives of a positive clinical learning environment; students feeling like learners and not workers; acknowledgement of contribution to patient care; feeling like part of the health care team; and finally, students would recommend the placement to other nursing students. 


\section{Results}

\section{Preceptor clinical supervision}

Figure 1 demonstrates that $100 \%$ of students "strongly agreed" or "agreed" that they were satisfied with their preceptor allocation. Ninety-six per cent of students "strongly agreed" or "agreed" that their preceptor showed a positive attitude towards supporting their learning needs and $94 \%$ of students "strongly agreed" or "agreed" that their preceptors were able to integrate theoretical knowledge into everyday clinical practice. The results of the open-ended questions consistently demonstrated that students evaluated their preceptors as displaying clinical excellence, were welcoming, helpful, confident, independent, exciting, explained clinical tasks, constantly learnt from their preceptors and that their preceptors were approachable, worked as a team, and took the time and effort to teach. The following narrative demonstrates the positive student-preceptor relationship and clinical supervision.

"I worked alongside [Sally and Joan] as preceptors. They were absolutely amazing and help[ed] develop my knowledge by facilitating my learning [and] by not always finding me the answers to my questions. Rather they gave me the tools to work things out. If I asked about a specific thing they guided me to the answer”.

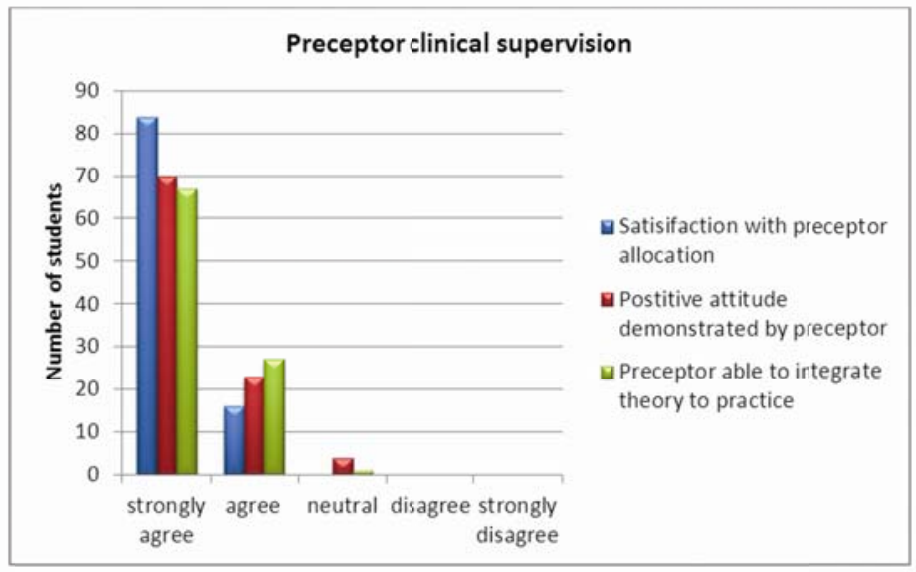

Figure 1. Student-preceptor Evaluations

\section{Facilitator clinical supervision}

Figure 2 demonstrates that 94\% of students "strongly agreed" or "agreed" that their relationship with their clinical facilitator was based on a relationship of respect and promoted their learning. Ninety-six per cent of students "strongly agreed" or "agreed" that their facilitator coordinated with clinical ward staff to support their learning objectives and 98\% of students "strongly agreed" or "agreed" that facilitators were able to integrate theoretical knowledge into everyday clinical practice. In relation to verbal and written feedback, 95\% of students "strongly agreed" or "agreed" about the appropriate timeliness of feedback from their facilitator. Nursing students described their facilitators as: encouraging; promoting their growth and development and extending their knowledge and promoting the students to ask questions, one student commented:

"I would like to thank my facilitator in particular. During the course of my clinical placement I was able to communicate with her on a day-to-day basis, making my facilitator very reliable. My facilitator was constantly supporting and encouraging the student experience during this placement. Furthermore, I feel I was able to reflect on my experience to my facilitator and I always received feedback from my facilitator regarding my nursing practice”. 


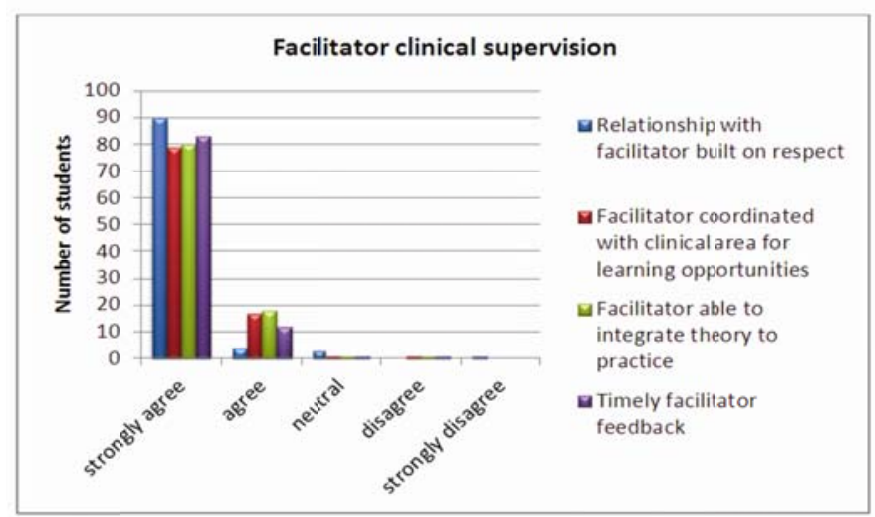

Figure 2. Student-facilitator Evaluations

\section{The clinical learning environment}

Figure 3 shows that $97 \%$ of students "strongly agreed" or "agreed" that the clinical environment motivated them as "learners". While 89\% of students "strongly agreed” or "agreed” that they were viewed as a "learner" $14 \%$ felt neutral about being seen as a "learner" rather than as an "extra worker". Ninety-eight per cent of students felt that their contribution to patient care was acknowledged and 96\% of students "strongly agreed" that they would recommend the clinical placement to other nursing students. Students described how the hospital's "clinical learning environment" consistently demonstrated a team-like environment. Students evaluated the clinical learning environment as dynamic, promoted progressive learning, created the opportunities to develop clinical skills, there were a variety of nursing opportunities, that the clinical placement was a great experience. Students also evaluated that the nursing staff had a professional demeanour, were warm, incredibly welcoming and helpful and that the overall experience was a "fantastic and great experience”. One student noted:

"I was aware of the good reputation St Vincent's Private has as a hospital (particularly a teaching one) before I started my placement but I can only say that it has been proven to me personally during my time here. Every member of staff made me feel welcome and openly encouraged me to question and learn as much as I could while on placement, even when clearly busy on the ward. I was really impressed by the great team environment and inclusive nature of the ward and would definitely recommend SVPH as a dynamic and progressive learning arena for student RNs. After five weeks I now feel confident in my decision to pursue nursing as a career path and much more developed in terms of both clinical skills and professional demeanour”.

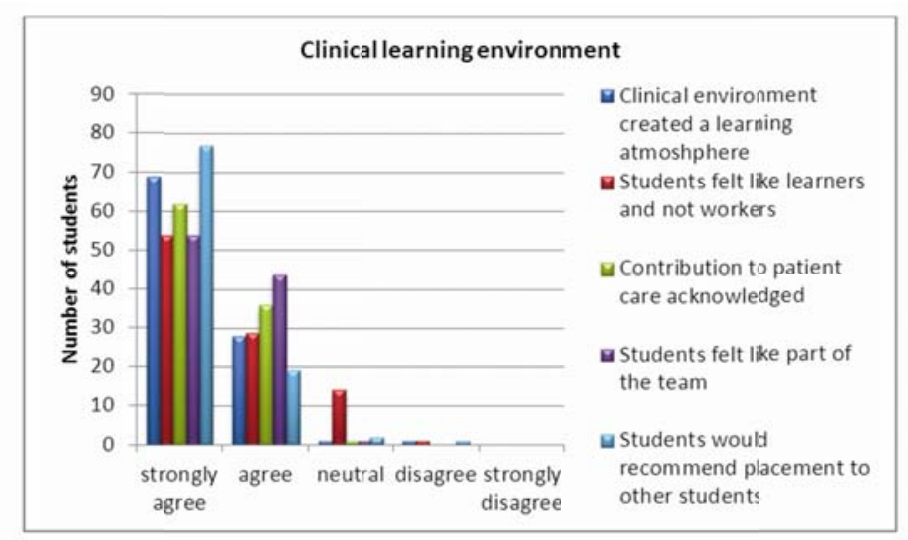

Figure 3. Clinical Learning Environment Evaluations 


\section{Discussion}

Three main themes emerged in relation to student evaluation of the preceptor, facilitator and the clinical learning environment. Firstly; the greatest amount of open-ended feedback from the nursing students related to the students' relationship with their clinical facilitator and the clinical supervision they received from their facilitator. This result confirms the findings within the literature that clinical supervision provided by clinical facilitators is rated more highly than that by preceptors ${ }^{[4]}$. This can be possibly due to clinical facilitators' greater understanding of students' stages of learning and learning objectives ${ }^{[4]}$. Secondly; positive and supportive relationships between students and their preceptors and facilitators are critical for quality clinical placements as students' rate support, respect and acceptance from more experienced nurses as being of major importance to them ${ }^{[2]}$. Equally, the literature is replete with descriptions of "support" being integral for nursing students while on clinical placement in so far as students consider "support" to be the most important facet of clinical supervision ${ }^{[20]}$. Thirdly; being part of the clinical team is vitally important to nursing students because without the sense of belonging their learning will be negatively impacted. St Vincent's Private Hospital, like many hospitals, is committed to a culture of promoting a positive learning environment for nursing students described as “necessary” by Health Workforce Australia ${ }^{[1]}$.

Undeniably, the provision of quality clinical supervision is a focus of education and health care providers not only in Australia, but internationally. With growing demands on fiscal and non-fiscal resources, maintaining quality patient care is imperative. With these issues in mind, both education and health care providers need to remain committed to clinical education and training while exploring innovative models of clinical supervision. Strong relationships between education and health care providers is crucial when addressing clinical placement capacity and capability and it is imperative that clinical placements offer students a safe, supportive and appropriately resourced learning environment. While there is a number of clinical supervision models used in the clinical learning environment, factors such as lack of preceptor training for nurses to take on the "teaching" and "assessment" role, demanding clinical workloads, increasing patient acuity and an increasing number of junior nurses entering the workforce, the preceptor-facilitator model used at St Vincent's Private Hospital offers not only more support and learning opportunities for nursing students but reduces the burden on clinical nurses who are attempting to juggle patient care and clinical supervision as a preceptor.

While this limited evidence to support the efficacy of the preceptor-facilitator clinical supervision model, this review offers both educational and health care providers an insight into a clinical supervision model that is highly regarded by nursing students. Not only does this clinical supervision model create a positive and supportive clinical learning environment that has a direct impact on the recruitment and retention of graduate nurses, this clinical supervision model offers more support to nurses in the preceptor role while offering clinical facilitators within the organisation continuing professional development opportunities, which in-turn increases staff satisfaction.

For future directions in the clinical learning environment, it is imperative that despite what clinical supervision model is used there is firstly a focus on educating, training and supporting nurses in the role as a preceptor. Secondly, educational and healthcare facilities consider their clinical facilitator recruitment strategy. Clinical facilitator recruitment from within the healthcare facility provides maximum support to nursing students and preceptors as the facilitator is familiar with the clinical learning environment. This familiarity also maximises patient safety as the facilitators are aware of the healthcare facilities policies and procedures and better positioned to be involved in direct patient care than sessional or academic facilitators.

\section{Limitations}

One limitation of this study is that it only takes into account the perspectives of nursing students and not the perspectives of preceptors or clinical facilitators. Another limitation of this study is while St Vincent's Private Hospital has a dedicated nurse educator who has a role in the clinical learning environment, the role of the nurse educator has not been explored. 
Further studies in relation to the perspectives of the preceptors, facilitators, educators and key stakeholders from both education and health care providers are required to more rigorously review and evaluate the preceptor-facilitator models. Factors such as facilitator secondment that may cause staffing shortages, facilitation "job" satisfaction and preceptors own sense of satisfaction in relation to student preceptoring, clinical workloads and preceptor "burnout" need to be explored further.

\section{Acknowledgement}

The authors of this paper would like to acknowledge and thank the education and research departments at St Vincent's Private Hospital for their contribution to this paper through the development of the student evaluation tool and provision of student evaluations.

\section{References}

[1] Health Workforce Australia (HWA). Clinical Supervision Support Programs: Directions Paper. 2011. http://www.hwa.gov.au/sites/uploads/clinical-supervision-support-program-directions-paper-april-2011.pdf

[2] Andrews GJ, Brodie DA, Andrews JP, Hillan E, Thomas BG, Wong J, et al. Professional roles and communications in clinical placements: A qualitative study of nursing students' perceptions and some models for practice. International Journal of Nursing Studies. 2006; 43: 861-874. PMid:16380124 http://dx.doi.org/10.1016/j.ijnurstu.2005.11.008

[3] Health Workforce Australia (HWA). Nursing Retention and Productivity in Spotlight. 2013. http://www.healthworkforceaustralia.com.au/hwinsights/issue9/index.html

[4] Brunero S, Stein-Parbury J. The effectiveness of clinical supervision in nursing: An evidenced based literature review. Australian Journal of Advanced Nursing. 2011; 25: 86-94.

[5] Bourgeois B, Drayton N, Brown, AM. An innovative model of supportive clinical teaching and learning in undergraduate nursing students. The cluster model. Nurse Education in Practice. 2011; 11: 114-118. PMid:21185231 http://dx.doi.org/10.1016/j.nepr.2010.11.005

[6] Butterworth CA, Faugier J. Clinical Supervision and Mentorship in Nursing. Chapman \& Hall. London.

[7] Heron J. Six-category intervention analysis. Human Potential Research Project. 1989. University of Surrey.

[8] Hawkins P, Shohet R. Supervision in the Helping Professions. 1989. Milton Keynes. University Press. United States of America.

[9] Waskett C. An integrated approach to introducing and maintaining supervision: The 4s model. Nursing Times. 2009 ; $105: 24-26$. PMid:19475911

[10] Winstanley J, White E. Clinical supervision models, measures and best practice. Nurse Researcher. 2002; 10: 7-38.

[11] Croxon L, Maginnis C. Evaluation of clinical teaching models for nursing practice. Nurse Education in Practice. 2009 ; 9: $236-243$. PMid:18722161 http://dx.doi.org/10.1016/j.nepr.2008.06.004

[12] Altmann TK. Preceptor selection, orientation, and evaluation in baccalaureate nursing education. International Journal of Nursing Education Scholarship. 2006; 3: 1-16. PMid:16646936 http://dx.doi.org/10.2202/1548-923X.1014

[13] Billay D, Myrick, F. Preceptorship: An integrative review of the literature. Nurse Education in Practice. 2008; 8: 258-266. PMid:17988946 http://dx.doi.org/10.1016/j.nepr.2007.09.005

[14] Callaghan D, Watts WE, McCullough DL, Moreau JT, Little MA, Gamroth LM, Durnford, KL. The experience of two practice education models: Collaborative learning unit and preceptorship. Nurse Education in Practice. 2009; 9: 244-252. PMid:18948062 http://dx.doi.org/10.1016/j.nepr.2008.08.010

[15] Henderson A, Twentyman M, Heel A, Lloyd B. Students' perceptions of the psycho-social clinical learning environment: An evaluation of placement models. Nurse Education Today. 2006; 26: 564-571. PMid:16675069 http://dx.doi.org/10.1016/j.nedt.2006.01.012

[16] Lillibridge J. Using clinical nurses as preceptors to teach leadership and management to senior nursing students: A qualitative descriptive study. Nurse Education in Practice. 2007; 7: 44-52. PMid:17689423 http://dx.doi.org/10.1016/j.nepr.2006.03.005

[17] Udlis KA. Preceptorship in undergraduate nursing education: An integrative review. Journal of Nursing Education. 2008; 47: 20-29. PMid:18232611 http://dx.doi.org/10.3928/01484834-20080101-09

[18] Holmlund K, Lindgren B, Athlin E. Group supervision for nursing students during their clinical placements: its content and meaning.Journal of Nursing Management. 2010; 18: 678-688. PMid:20840362 http://dx.doi.org/10.1111/j.1365-2834.2010.01157.x

[19] Lindgren B, Athlin E. Nurse lecturers' perceptions of what baccalaureate nursing students gain from clinical group supervision. Nurse Education Today. 2010; 30:360-364. PMid:19818540 http://dx.doi.org/10.1016/j.nedt.2009.09.008

[20] Walker S, Dwyer T, Moxham L, Broadbent M, Sander T. Facilitator versus preceptor:

Published by Sciedu Press 
Which offers the best support to undergraduate nursing students? Nurse Education Today. 2012. Article in press: 1-6.

[21] O’Brien L, Buxton M, Gillies D. Improving the undergraduate clinical placement experience in mental health nursing. Issues in Mental Health Nursing. 2010; 29: 505-522. PMid:18437609 http://dx.doi.org/10.1080/01612840801981355

[22] Mannix J, Faga P, Beale B, Jackson D. Towards suitable models for clinical education in nursing: An ongoing conversation. Nurse Education in Practice. 2006; 6: 3-11. PMid:19040850 http://dx.doi.org/10.1016/j.nepr.2005.05.004

[23] Lofmark A, Thorkildsen K, Raholm M, Natvig GK. Nursing students' satisfaction with supervision from preceptors and teachers during practice. Nurse Education in Practice. 2012; 12: 164-169. PMid:22225731 http://dx.doi.org/10.1016/j.nepr.2011.12.005

[24] Health Workforce Australia. National Clinical Supervision Support Framework - Consultation. 2011. https://www.hwa.gov.au/sites/uploads/national-clinical-supervision-support-framework-consultation-draft-april-2011.pdf

[25] Chan D. Development of an innovative tool to assess hospital learning environments. Nurse Education Today. 2001; 21: 624-631. PMid:11884175 http://dx.doi.org/10.1054/nedt.2001.0595 